\title{
PARALYTIC CLAW HAND
}

\author{
With Special Reference to Paralysis in Leprosy \\ and Treatment by the Sublimis Transfer of Stiles and Bunnell
}

\author{
Paul W. Brand, Vellore, India \\ Professor of Orthopaedic Surgery, Christian Medical College and Hospital, Vellore, South India
}

It is only occasionally that the human hand is used for scratching. In this action the finger nails are the essential instruments, and the pulps are only in the way. Animals of the cat tribe who depend so much on their claws in battle, and animals who use them for digging, like the mole, depend mainly on their profundus muscles to bring their claws into action. They could probably fight and dig without their intrinsic muscles. The spread and retraction, but not the effectiveness, of their claws would be lost.

In the human hand the function of the nails has been superseded by that of the pulp. This beautiful organ of discrimination and power brings to our knowledge the texture of our environment; it is also the means by which we impose our will on the tools that subdue and transform the world for our pleasure.

When the intrinsic muscles of the human hand are paralysed, the power of the grasp is not much affected. There are four main disabilities: 1) The fingers cannot be opened out fully at the interphalangeal joints; 2) the power of abduction and adduction is lost; 3) in grasping an object, flexion begins at the terminal joints, closing the fingers on themselves rather than on the palm; 4) the effective part of the finger becomes the tip and the nail (claw) rather than the pulp.

The first two disabilities have received most of the attention in the literature. Considered functionally, however, the last two matter most.

\section{ANATOMY}

The anatomy of intrinsic muscle action has been fully and beautifully analysed by Bunnell (1948), Kaplan (1953), Littler (1949) and others. We do not need to attempt an analysis here, but the following points need emphasis.

Metacarpo-phalangeal joint-The intrinsic muscles are the only prime flexors of the metacarpophalangeal joints. The long flexor muscles do flex these joints, but only secondarily; their first action is on the interphalangeal joints. In intrinsic palsy the metacarpo-phalangeal joints have no prime flexor, but retain a powerful extensor, the extensor digitorum.

Interphalangeal joints - In the normal hand these joints may be extended by the unaided action of the intrinsic muscles acting through the lateral band, which lies just dorsal to the joint fulcrum. They may be extended also by the action of the long extensors, provided the intrinsic muscles stabilise the metacarpo-phalangeal joint.

In the absence of the intrinsic muscles the interphalangeal joints have no prime extensor. The attempt to straighten the whole hand leads only to hyperextension of the metacarpophalangeal joints until their anterior capsules limit the backward movement. At this stage the residual power of the long extensors may partly extend the interphalangeal joints against the resistance of the overstretched long flexors. As soon as the metacarpo-phalangeal hyperextension is relaxed in beginning to close the hand, the interphalangeal joints again lose all extensor power. The patient therefore always closes his hand by closing his terminal joints first. This means that unless an object is small enough to be grasped by the curve of 
set up in front of him and is told to imitate the pictures on the chart. The photographer also demonstrates with his own hand the position he is to attempt. The six standard positions are: 1) "Hold your hand quite straight at all joints." 2) "Bend at the metacarpo-phalangeal joints and straighten all interphalangeal joints." 3) "Close your fist." 4) "Hold up your thumb at right angles to your hand." 5) "Pinch firmly between index finger and thumb." 6) "Bring your thumb across your palm to the base of the little finger." The photographs include a card with date and number.

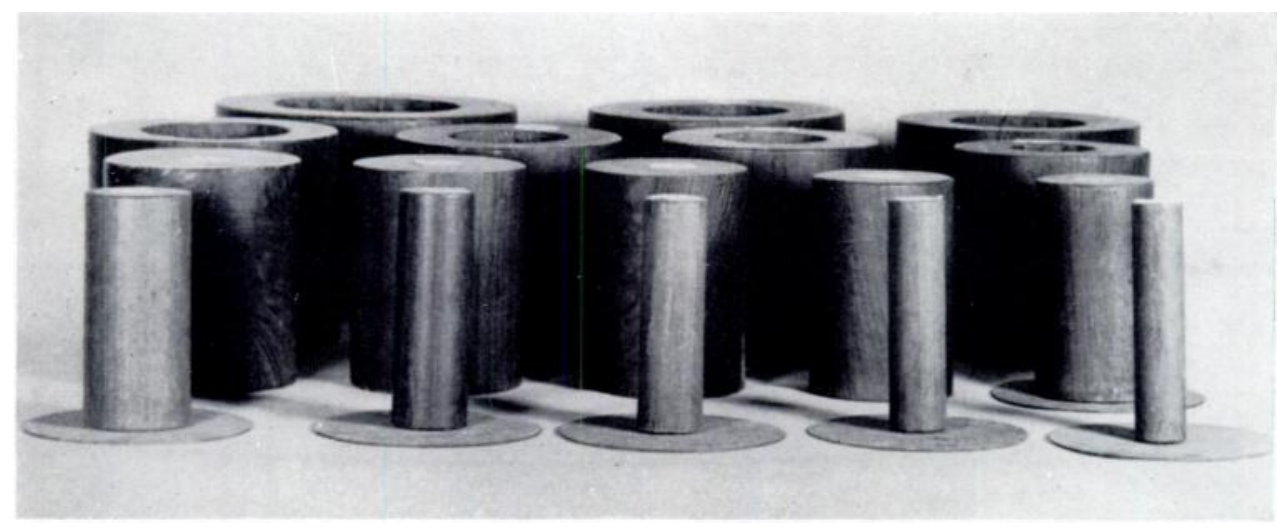

FIG. 5

Wooden cylinders for assessing grasp index. It is important that the cylinders should not be fixed or stabilised for the patient. Otherwise he will use the cylinders as a fulcrum and extend his fingers passively.

\section{RESULTS}

It is not easy to group together a mass of figures of angles so that they mean something intelligible in terms of success and failure. In this study we have grouped the results as Excellent, Good, Fair and Poor.

The division is bound to be arbitrary and to depend upon our own conception of what we are trying to achieve. It also depends upon what one considers it possible to achieve. For example, it could be argued that it is not reasonable to expect a tendon transfer to move a joint beyond its pre-operative passive range. Therefore, an "excellent" result would be to produce active movement through the whole range of pre-operative passive movement. This is reasonable, but our later results have sometimes shown better-than-excellent results by this standard.

We have chosen in this study to work to absolute standards and not to call a result excellent unless full range has been obtained, however bad the contracture at the time of operation. We have analysed separately the results of operation on different pre-operative types of hands. Results have been analysed to show: 1) The ability of the patient to open his hand fully; 2) the ability of the patient to close his fist fully; 3 ) the restoration of the correct mechanics of closing the hand (lumbrical movement); 4) absence of abnormal lateral deviation; 5) the patient's own opinion; and 6) the summation of all the above in an overall impression.

\section{THE OPEN HAND ASSESSMENT}

To score "excellent" a patient, with hand previously clawed, must be able to open his hand absolutely straight with no single degree of residual flexion at the proximal interphalangeal joint. In position 1 of the standard diagrams for photographs he is allowed to attempt this movement freely, but in position 2 and during measurement he has the restriction that he is not allowed to extend the metacarpo-phalangeal joint while extending the interphalangeal 

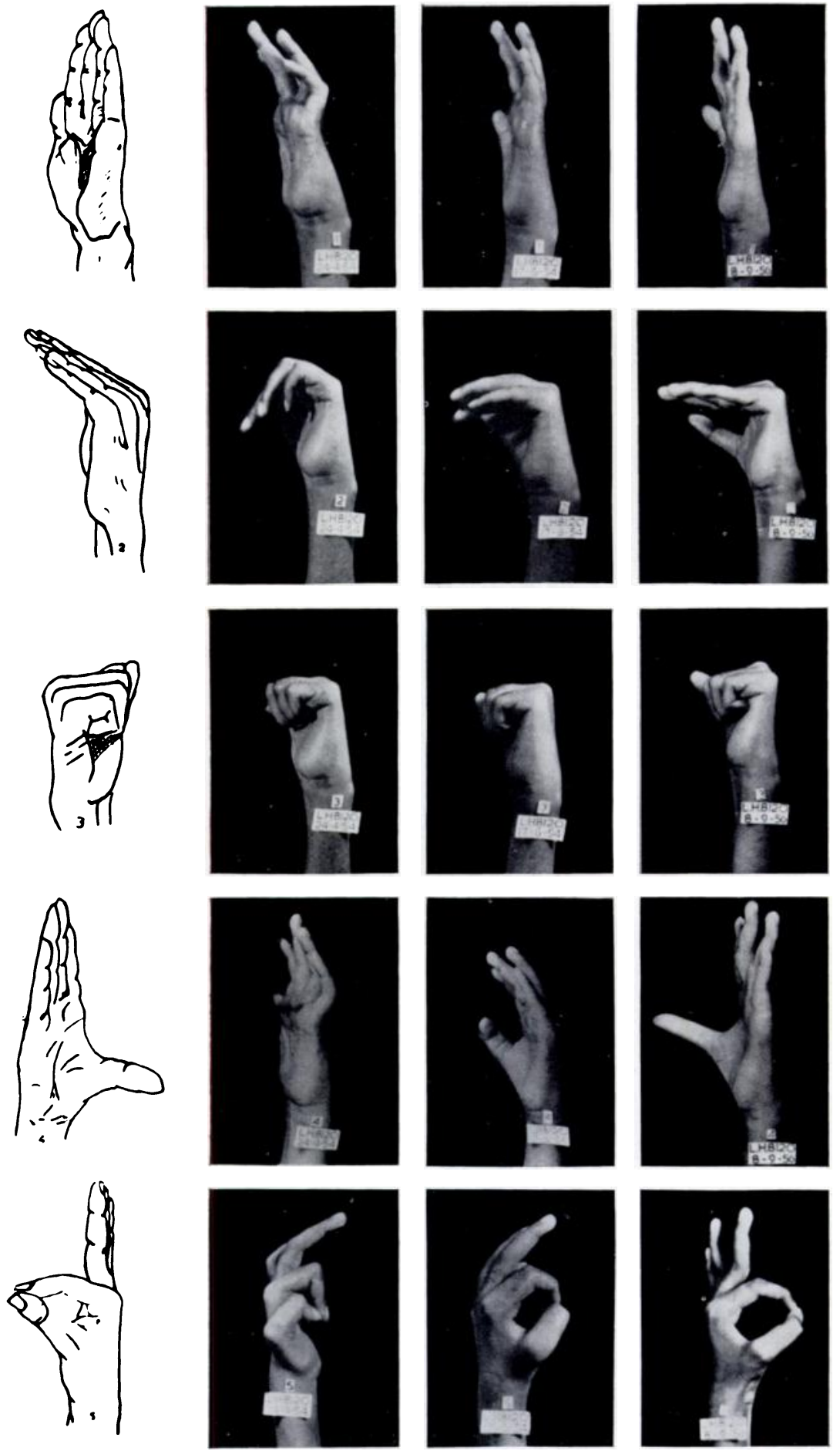

Fig. 6

A typical photographic record. Every patient has exactly this type of photographic record. Column 1, diagrams. Column 2, before operation. Column 3, after operation. Column 4, follow-up (two years later). Notice how the results improve with time. In row 2 , illustrating metacarpo-phalangeal flexion with interphalangeal extension, the post-operative result might be classed as good. In the later follow-up it would be excellent if it were not for commencing "intrinsic plus" deformity. In row 3, illustrating the closed fist, the post-operative photograph shows some residual stiffness. A later follow-up shows a normal fist. In row 5, the later follow-up demonstrates the " intrinsic plus" deformity of the middle finger. This patient has also had an abductor replacement operation for his thumb. (Action of the thumb has not been considered in this publication, and the relevant photographs are therefore omitted.)

THE JOURNAL OF BONE AND JOINT SURGERY 
joints-that is, it has to be a true "lumbrical action." The title to excellence is lost if the finger bends backwards (" more than straight") on attempting to straighten the finger, or if there is significant ulnar or radial deviation of the finger on straightening.

To score " good" the hand should open out enough for all ordinary function, and enough to appear normal at rest. A normal resting hand may be 30 degrees flexed when measured along the dorsum. It is uncommon to require more than 150 degrees of opening at the interphalangeal joints in grasping the largest objects. To score " good" in our series a finger must open out to at least 150 degrees unassisted. A " good " finger may show perceptible but not gross terminal joint flexion, or it may show slight lateral deviation if it can be fully and normally straightened, but if it shows the slightest limitation of extension and has lateral deviation, then it is classed as "fair."

To score "fair" a finger must show improvement over pre-operative figures, and must extend to 120 degrees without lateral deviation. A fully straight finger scores only "fair" if there is a definite lateral deviation, or if it bends backwards into marked "intrinsic plus."

Any finger that does not score " fair" even if it is better than before operation is classed as "poor."

Table II is an analysis of the success of the sublimis transfer to produce a fully open hand with straight, undeviated fingers: 73 per cent of fingers have scored a good or excellent result. This may be further analysed in an attempt to understand the causes of failure and to be able to predict the degree of probable success in any given case.

TABLE II

Open Hand Assessment

\begin{tabular}{|c|c|c|c|c|}
\hline Finger & $\begin{array}{l}\text { Excellent } \\
\text { (per cent) }\end{array}$ & $\underset{(\text { per cent })}{\text { Good }}$ & $\begin{array}{c}\text { Fair } \\
\text { (per cent) }\end{array}$ & $\begin{array}{c}\text { Poor } \\
(\text { per cent })\end{array}$ \\
\hline Index (130) & 29 & 48 & 21 & 2 \\
\hline Middle (134) & 32 & 43 & 23 & 2 \\
\hline Ring (150) & 36 & 39 & 21 & 4 \\
\hline Little (150) & 26 & 38 & 30 & 6 \\
\hline Average & 31 & 42 & 24 & 3 \\
\hline
\end{tabular}

Fingers that were stiff before operation showed a much higher proportion of extension limitation after operation than the mobile fingers. This is not surprising. Further analysis shows that 76 per cent of all patients achieved a post-operative unassisted angle that was as good as, or better than, the pre-operative assisted angle. Ninety per cent showed a postoperative angle that was within 20 degrees of the pre-operative assisted angle. The failures (10 per cent) as judged by this standard were further studied, and in an unselected group of five cases in which there was a post-operative contracture more gross than the pre-operative assisted angle exploration was carried out. In every case it was found that the stumps of the sublimis tendons left behind in the flexor sheath had grown across the interphalangeal joint and attached themselves to the sheath, proximal to the joint. They thus formed a sort of bowstring across the joint, preventing extension. On cutting and excising the bowstring the joint could be extended. This complication has been predicted by Bunnell in his writings. We have found that it has occurred less frequently since we have taken care to divide the sublimis exactly at its insertion. 
Apart from this complication, it appears that really the only cause of failure to produce full extension by this operation is the presence of pre-operative contracture or pre-operative defect in the continuity of the dorsal expansion (Fig. 7). This later defect is sometimes present in lepromatous cases, and also occurs as a result of old injury or infection on the dorsum of

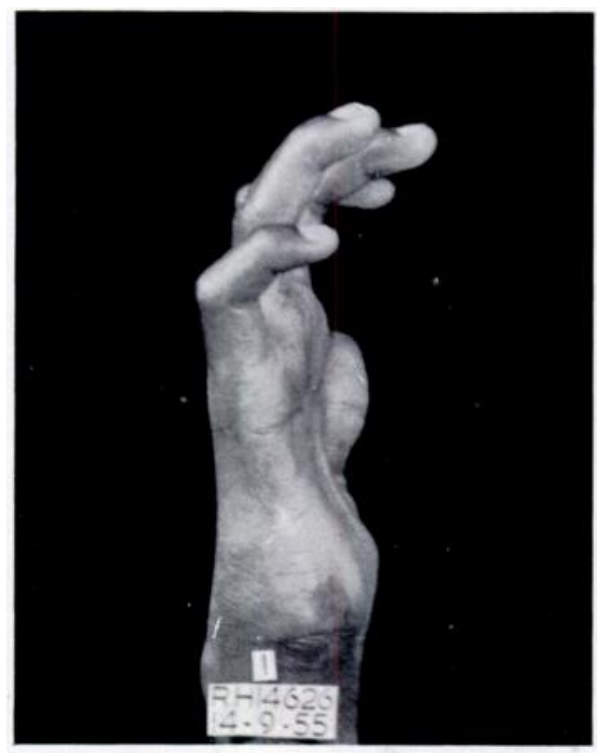

Fig. 7

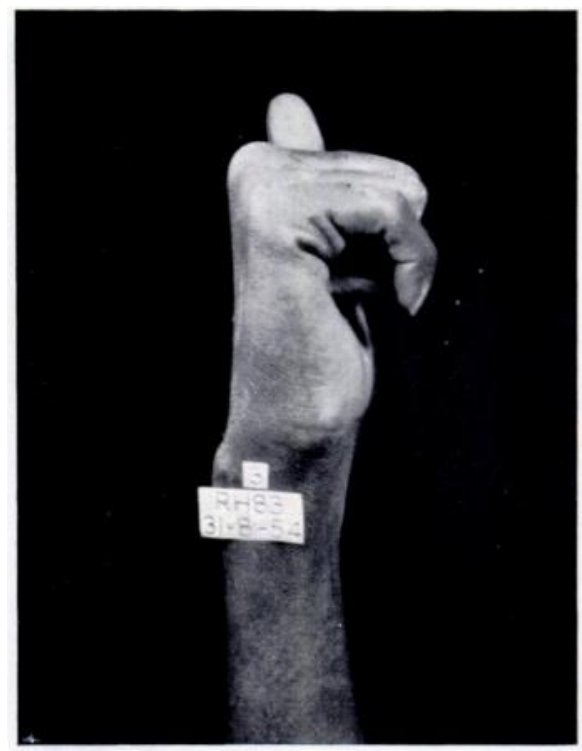

FIG. 8

Figure 7-Incomplete extension of the interphalangeal joints in a hand which had pre-operative contractures. This is a common complication. Figure 8-Imperfect closure of the fist after operation in a patient who before operation had ulnar profundus weakness.

the finger. Such a defect can be assumed to be present when the pre-operative "assisted" angle is very different from the "contracture" angle. The defect must be repaired or the operation will be a failure.

In Table III we have grouped our cases according to their pre-operative mobility. Hypermobile implies a good finger with joints that will bend backwards slightly on passive

TABLE III

StATE OF Fingers before Operation

\begin{tabular}{|c|c|c|c|c|c|}
\hline \multirow[b]{2}{*}{ Finger } & \multirow{2}{*}{$\begin{array}{l}\text { Hypermobile } \\
\text { (per cent) }\end{array}$} & \multirow{2}{*}{$\begin{array}{l}\text { Mobile } \\
\text { (per cent) }\end{array}$} & \multirow{2}{*}{$\begin{array}{l}\text { Defective } \\
\text { (per cent) }\end{array}$} & \multicolumn{2}{|c|}{ Contracted } \\
\hline & & & & $\begin{array}{c}\text { Mild } \\
\text { (per cent) }\end{array}$ & $\begin{array}{c}\text { Marked } \\
\text { (per cent) }\end{array}$ \\
\hline Index (130) & 8 & 44 & 22 & 17 & 9 \\
\hline Middle (134) & 14 & 32 & 34 & 10 & 10 \\
\hline Ring (150) & 12 & 30 & 31 & 17 & 10 \\
\hline Little (150) & 4 & 34 & 35 & 17 & 10 \\
\hline Average & 9 & 35 & 31 & 15 & 10 \\
\hline
\end{tabular}

pressure. Such fingers are very common in India where slim, mobile fingers are highly prized. Finger gymnastics form a common part of Indian classical dancing. This dancing demands supple, fluid finger movements which most westerners find impossible to imitate. The mobile group includes fingers that could be fully straightened passively. The defective group comprised 


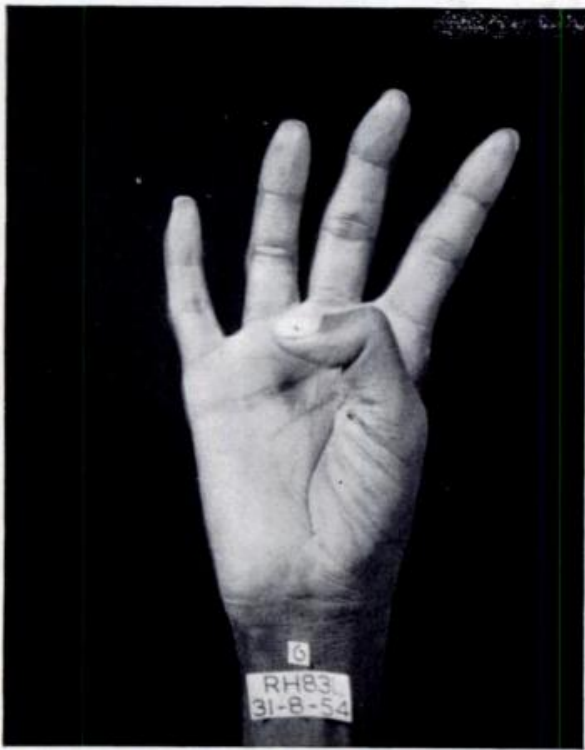

Fig. 9

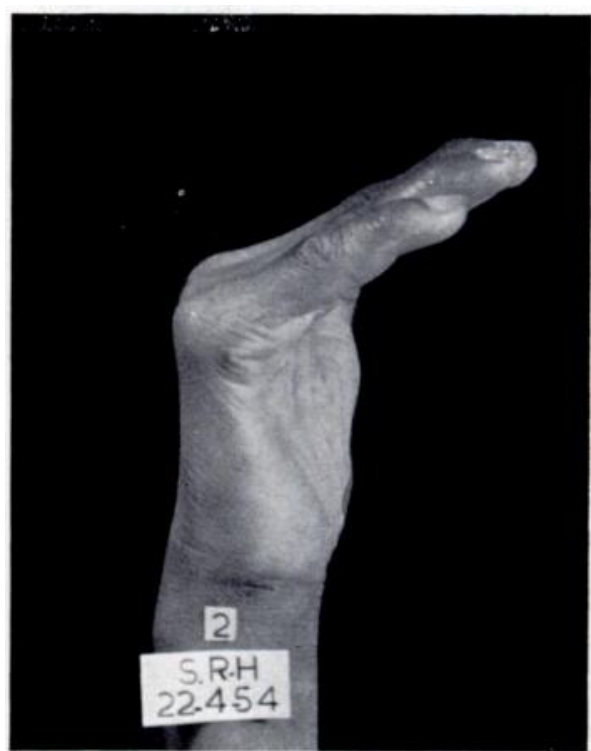

Fig. 10

Figure 9-Radial deviation of the fingers. An occasional complication after the sublimis has been sutured to the radial side of the finger. Figure 10-Terminal joint flexion. This occurs in almost every sublimis replacement operation after a year or two.

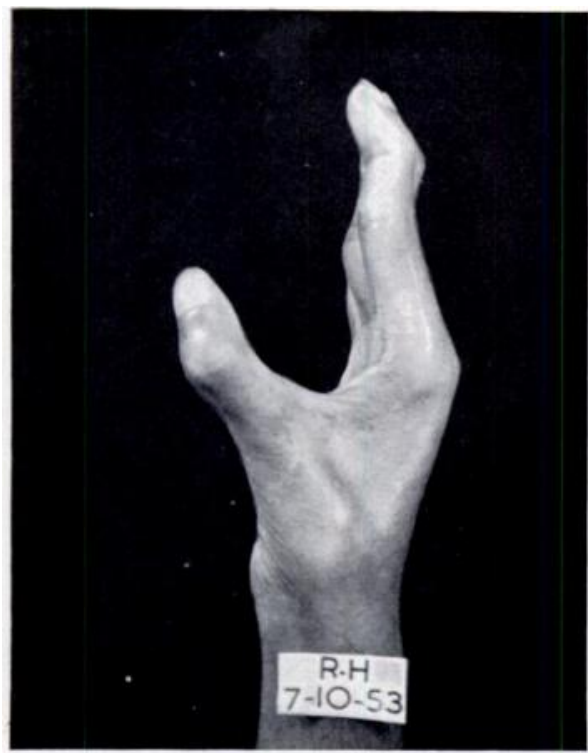

Fig. 11

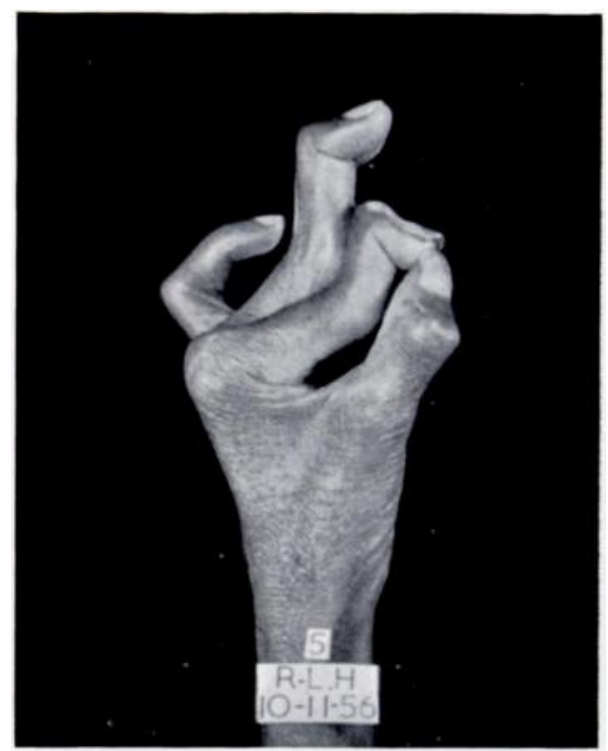

Fig. 12

Figure 11-Moderate degree of " intrinsic plus." Hyperextension of the proximal interphalangeal joint and flexion of the terminal joint. This complication is fairly common in mobile hands. Figure 12-Severe degree of " intrinsic plus." This hand in the first year after operation was classed as an excellent result. In the following two years it has developed an ugly and disabling deformity. This degree of "intrinsic plus" is uncommon. 
fingers with a full range of passive movement but with a failure in the assisted angle-that is, defect in the dorsal expansion. A mild contracture was classed as a lack of passive extension less than $\mathbf{3 0}$ degrees. A marked contracture was one of more than $\mathbf{3 0}$ degrees.

Complications-The " intrinsic plus" deformity is a very interesting one, and its management deserves separate consideration, but a few points must be mentioned here. The name " intrinsic plus" was first used by Bunnell to describe the effect on the hand of an ischaemic contracture of the intrinsic muscles. The features of the condition (Figs. 10 to 12) are as follows: 1) the proximal interphalangeal joint is hyperextended. 2) If the metacarpo-phalangeal joint is held in extension it becomes impossible to flex the proximal interphalangeal joint, even passively. This is the "intrinsic plus sign."

If a sublimis tendon is removed from its insertion in an otherwise normal finger (as in cases where it is to be used as an abductor of the thumb), there often follows a slight deformity marked by a tendency to flexion of the terminal joint and a slight hyperextension at the proximal interphalangeal joint. This deformity never goes on to a fully developed " intrinsic plus" and the interphalangeal joints can be fully flexed passively, even with the metacarpophalangeal joints extended. If, however, the sublimis is transferred to the lumbrical insertion, as for intrinsic palsy, a very powerful muscle that was previously a flexor now becomes an extensor of the same joint and leaves that joint with no prime flexor. The profundus muscle takes over the flexor function, but is now an opponent of the sublimis, with which it previously acted synergistically. Re-education of the sublimis and profundus to act reciprocally after the Stiles-Bunnell operation is very difficult. In many cases true reciprocal action never occurs, even though lumbrical action is achieved. If the tendon transfer is made with the sublimis at neutral tension the operation is a failure. If the sublimis is sutured at higher tension than the profundus the operation is a success in that the claw hand is corrected but there seems to be a continued tonus of the sublimis as a background to all finger movement. During closure of the fingers the profundus seems to have to overcome the resistance of the sublimis at the proximal interphalangeal joint before that joint will bend. It succeeds because the mechanical advantage of the flexor tendons at that joint is greater than that of the lateral band.

If the finger is a stout and stable one this muscle conflict does not seem to matter, and if there is some degree of stiffness in the clawed position there may be definite advantage in this continuous corrective pull by a powerful muscle. In a flexible, mobile finger, however, we regularly see a year-by-year tendency to develop hyperextension of the proximal interphalangeal joint and flexion of the terminal joint. If the patient keeps his fingers mobile by exercises and passive movement he may avoid the second feature of "intrinsic plus," the inability to flex the interphalangeal joint even passively when the metacarpo-phalangeal joints are extended. In the absence of such regular movements, the full " intrinsic plus " picture may be developed.

Considered functionally, the " intrinsic plus" hand is fairly useful, and far better than the claw hand that it has replaced. It is ugly, however, and a definite source of weakness, especially in pinch against the thumb (Fig. 12). The seriousness of this deformity was not recognised early because it is seldom noticeable during the first year. The worst cases are seen in the third and fourth years, and most really mobile hands develop at least a mild degree of it after a few years. The deformity is correctable to some extent. We have found that Littler's operation is satisfactory for these cases, but it needs to be supplemented by a tenodesis of the profundus tendon in the middle segment of the finger, with the terminal joint nearly extended, or else the deformity will recur. (This tenodesis would not be necessary in the contracture cases for which Littler's operation was first designed.)

Comment-As this complication occurs in the best and most mobile hands and those that should carry the best prognosis, we have felt it right to abandon the sublimis transfer operation completely for mobile hands during the past year. The operation is probably still the best for the claw hand with contracture because it provides a very powerful corrective, but for mobile 
hands it should be displaced by Fowler's operation or by a new operation developed in this unit. We now use free grafts from the extensor carpi radialis brevis. Neither of these operations requires the removal of the sublimis and neither of them is followed by "intrinsic plus" deformity. An analysis of the results of these operations will be published shortly.

We are in a position to say, however, that Fowler's operation is not as good as the Stiles-Bunnell operation for the stiff hand, and it is sometimes disappointing for a few months after operation. The results improve with time, however, especially if the tendon is sutured under fairly high tension (enough to make metacarpo-phalangeal extension difficult in the early post-operative phase), and if care is taken to provide adequate extensor communis action for the little finger, after removal of the extensor digiti minimi.

Our own operation uses the same principle as the Fowler's procedure, in that the new tendon is passed from the dorsum of the hand through the interosseous space, anterior to the transverse metacarpal ligament and sutured to the lumbrical insertion. We use the extensor carpi radialis brevis as the motor muscle and extend its tendon with a four-tailed free graft. The action of a wrist extensor can very easily develop a natural synergism with lumbrical movement. In this operation, also, the action of the hand improves with time. In all our hand reconstructions so far the most perfect approximations to normal finger action have followed this new procedure.

Lateral deviation (Fig. 9)-Abduction and adduction movements of the fingers are functions of the intrinsic muscles. To produce an " excellent " result one should perhaps restore these movements also.

In Bunnell's account of his operation he suggested that the sublimis tendons might be split so that each tendon is attached only to the radial, or only to the ulnar side of adjacent fingers. In this way lateral movement might be restored. It was an ingenious suggestion, but he did not state whether he had ever actually achieved this object. We tried this method a few times some years ago and gave it up because abduction and adduction movements were not obtained. As we looked at the operative field and saw split tendon-slips criss-crossing each other in the palm without intervening soft tissue, it seemed improbable that each slip would move independently of the others. It may be that re-education was at fault. We would be glad to hear of the experience of others. Since 1951 we have been transferring only one sublimis slip to each finger and attaching it to the radial side of the dorsal expansion.

We are satisfied with this method for these reasons: 1) It obviates the need for four incisions on the fingers and shortens operating and tourniquet time; 2) it saves a sublimis tendon which can be used for restoring opposition and abduction to the thumb; 3) it allows another sublimis to be left in the little finger in case of profundus weakness, or in the index finger to strengthen its power of pinch.

On reviewing our cases on a long-term basis we find that 19 per cent show a significant radial deviation and 4 per cent deviate enough to give a deformed appearance. The reason we first chose the radial-side insertion was that it seemed reasonable to have the index finger stabilised on the radial-side to resist the tendency of the thumb to push it medially in pinching.

It has often been stressed that if the first dorsal interosseous muscle is weak a radial-side muscle transfer to the index finger is needed to reinforce the pinch by restoring abduction to that finger.

We have found that one of the disabilities in hands that have been reconstructed after ulnar-median palsy is that the index and middle fingers tend to separate from each other. The anaesthetic tip of the thumb slips in between the index and middle fingers. We have therefore recently begun to insert the index finger sublimis transfer into the ulnar side of the index finger and all the other sublimis slips into the radial side of the other fingers. This has kept the index and middle fingers together and made a very good tripod pinch between thumb, index and long fingers. It also gives a much better appearance to the hand as a whole. The effect of this change on the strength of the pinch will be analysed in a later communication.

VOL. $40 \mathrm{~B}$, NO. 4 , NOVEMBER 1958 
The change in insertion is too recent to affect the results in this study, which represents the results of radial-side insertion of the transferred tendon.

\section{CLOSED FIST ANALYSIS}

Most patients with claw hand can close their fingers fully before operation except when profundus weakness in the ring and little fingers makes it difficult to flex the terminal phalanges (Fig. 8).

If the fingers cannot close after operation the failure must be due to the operation. Sometimes it may be due to loss of flexion power owing to the transference of the sublimis from its usual place. This is true only of those cases in which there is an additional profundus weakness in two fingers.

An " excellent" category implies a tight fist, with the finger tips fully tucked into the base of each finger. A knitting needle must be grasped and held firmly in the curve of the finger. A "good" assessment means that the finger closes fully but not tightly enough to hold a needle in its curve. "Fair" means that a gap is visible between base of finger and tip but the tip meets the palm farther down. "Poor" means that the finger tip does not meet the palm (Table.IV).

TABLE IV

Closed Fist

\begin{tabular}{|c|c|c|c|}
\hline $\begin{array}{l}\text { Excellent } \\
\text { (per cent) }\end{array}$ & $\underset{\text { (per cent) }}{\text { Good }}$ & $\begin{array}{c}\text { Fair } \\
\text { (per cent) }\end{array}$ & $\begin{array}{c}\text { Poor } \\
\text { (per cent) }\end{array}$ \\
\hline 39 & 33 & 23 & 5 \\
\hline
\end{tabular}

MECHANISM OF CLOSING

This is a vitally important assessment so far as function is concerned. Results were graded as follows: Excellent-Starting from the position of maximal straightness of that finger (even if that is not excellent), the patient can flex the finger first at the metacarpo-phalangeal joints and can complete its metacarpo-phalangeal flexion before the interphalangeal joints begin to flex.

TABLE V

Mechanism of Closing

\begin{tabular}{|c|c|c|c|}
\hline $\begin{array}{l}\text { Excellent } \\
\text { (per cent) }\end{array}$ & $\underset{\text { (per cent) }}{\text { Good }}$ & $\begin{array}{c}\text { Fair } \\
\text { (per cent })\end{array}$ & $\begin{array}{c}\text { Poor } \\
\text { (per cent) }\end{array}$ \\
\hline 57 & 36 & 5 & 2 \\
\hline
\end{tabular}

A finger that cannot be fully straightened but which closes with the correct sequence of movement is more useful than a straight finger that closes its interphalangeal joints first when beginning to grasp.

Good-One in which interphalangeal flexion begins just before metacarpo-phalangeal flexion is complete.

Fair-One in which interphalangeal flexion begins and continues along with metacarpophalangeal flexion. "Fair" is quite satisfactory for most activity. In fact, it is the mechanism used in the normal hand for grasping small objects. However, it represents a failure to reach a defined standard after operation.

Poor-Metacarpo-phalangeal flexion is delayed behind interphalangeal flexion. The results are shown in Table V. 
It will be noticed that the Stiles-Bunnell procedure gives a very good mechanism of closing. A defect in some of these hands which we have not recorded is that the patient cannot close his interphalangeal joints before the metacarpo-phalangeal joints even if he wants to (latent form of " intrinsic plus"). It is associated with the loss of the sublimis from its normal situation. This defect is noticed in typing and piano playing.

\section{DISCUSSION}

In reviewing the statistics of the results of the sublimis transfer operation one may feel it has been highly successful. Three-quarters of all cases have given an excellent or good result considered in terms of the open hand, irrespective of the fact that many patients have had pre-operative contracture. The correct mechanism of closing has been restored in more than 90 per cent of cases. One may feel that these figures would be hard to better with any other operation.

However, as we look back on these 150 cases and also on the many other hands that we have seen after operation but which we were not able to re-examine for this study, we do not feel satisfied.

The reason for the remarkable success of the operation is also the source of its greatest weakness. A very powerful muscle, with a big amplitude, like the sublimis digitorum, is used to do the work of a very small muscle, the lumbrical, which has a short range of action. The sublimis transfer, therefore, nearly always achieves its purpose. As time goes on, however, it often more than achieves it and produces secondary deformities. Conversely, the absence of the sublimis from its normal situation produces a weakness in pinch and to a lesser extent in grasp that is significant. We feel that we are now in a position to lay down definite indications for the use of the Stiles-Bunnell operation.

In all cases in which there is a significant contracture at the proximal interphalangeal joint and in which the contracture cannot be fully overcome before operation, the sublimis transfer is the operation of choice. Its powerful corrective effect may produce results that are better than could be predicted from the limited pre-operative range of movement. In stable hands with no range of passive hyperextension of the interphalangeal joints a sublimis transfer under moderate tension will usually give a good result although an operation which avoids the removal of the sublimis tendon would give a stronger and more useful hand.

For hypermobile, flexible fingers the sublimis transfer is contra-indicated. For this type of hand better results will be achieved by Fowler's operation or by the four-tailed graft from the extensor carpi radialis brevis referred to earlier.

\section{SUMMARY}

1. The intrinsic paralysis that occurs in leprosy has been treated by the sublimis transfer of Stiles and Bunnell for the past nine years. Since 1951300 hands have been operated upon, and 150 patients selected geographically have been followed up in this study.

2. The patients have been assessed by a standard method involving: 1) Measurement of range of movement of the interphalangeal joint (unassisted movement, assisted active movement and passive movement);2) grasp index; and 3) photographs of each hand in six standard positions.

3. Assessment of the open hand-The Stiles-Bunnell procedure is effective in achieving a fully open hand: 73 per cent of the fingers scored good or excellent results. A defect in the operation is that it sometimes hyperextends the interphalangeal joint, producing an " intrinsic plus" hand.

4. Assessment of sequence of joint flexion-The Stiles-Bunnell operation restores satisfactory mechanism of closure of the hand in 93 per cent of cases-that is, the metacarpo-phalangeal joints flex before the interphalangeal joints.

VOL. $40 \mathrm{~B}$, NO. 4, NOVEMBER 1958 
5. The closed fist assessment-About 30 per cent of patients had some defect in the complete closure of the fist after operation. In 5 per cent of cases the fingers did not reach the palm after operation.

6. Complications-The " intrinsic plus" defect is commonest in the best and most mobile hands. This is a late complication which gets worse in succeeding years. It can be corrected by Littler's operation together with a profundus tenodesis in the middle segment of the finger. Lateral deviation of fingers due to radial-side attachment of the transferred tendon can be avoided by ulnar-side attachment of the tendon used for the index finger. Bowstringing of the sublimis stump in the flexor sheath may be avoided by division of the sublimis at its insertion. Weakness of grasp and pinch from loss of sublimis may be avoided by using only one or two sublimis tendons split into several strands. The index finger sublimis should be left in position.

7. It is concluded that the sublimis transfer of Stiles and Bunnell is a very powerful corrective of intrinsic paralysis of the fingers. Its chief defect is that it is too powerful and produces the opposite deformity. For this reason the use of this operation should be restricted to fingers in which there is some limitation of passive extension. For fully mobile fingers an operation should be selected which does not remove the sublimis from its normal position.

Most of these operations have been performed by a series of assistants and trainees in hand surgery. I wish to thank them for the enthusiasm and meticulous care in record keeping which has made this study possible. I also wish to record my appreciation of the sterling work of our records clerk, Mr Furness, who has travelled many miles in seeking out changed addresses. I would like to thank Mr Guy Pulvertaft for his helpful criticism of this article.

\section{REFERENCES}

Brand, P. W. (1952): The Reconstruction of the Hand in Leprosy. (Hunterian Lecture.) Annals of the Royal College of Surgeons of England, 11, 350.

Brand, P. W. (1954): Hand Reconstruction in Leprosy. In British Surgical Practice. Surgical Progress 1954, p. 117. London: Butterworth \& Co. (Publishers) Ltd.

Bruner, J. M. (1953): Problems of Postoperative Position and Motion in Surgery of the Hand. Journal of Bone and Joint Surgery, 35-A, 355.

Bunnell, S. (1942): Surgery of the Intrinsic Muscles of the Hand Other Than Those Producing Opposition of the Thumb. Journal of Bone and Joint Surgery, 24, 1.

Bunnell, S. (1948): Surgery of the Hand. Second edition. Philadelphia: J. B. Lippincott Company.

BunNell, S. (1953): Ischaemic Contracture, Local, in the Hand. Journal of Bone and Joint Surgery, 35-A, 88. DeHIO, K. (1897): Ueber die Lepra anaesthetica und den pathogenetischen Zusammenhang ihrer Krankheitserscheinungen. Mittheilungen und Verhandlungen der internationalen wissenschaftlichen Lepra-Conferenz zu Berlin im October 1897. Band 2, p. 85. Berlin: August Hirschwald.

Eyler, D. L., and MARKeE, J. E. (1954): The Anatomy and Function of the Intrinsic Musculature of the Fingers. Journal of Bone and Joint Surgery, 36-A, 1.

Fowler, S. B. (1949): Extensor Apparatus of the digits. Journal of Bone and Joint Surgery, 31-B, 477. Goldner, J. L. (1953): Deformities of the Hand Incidental to Pathological Changes of the Extensor and Intrinsic Muscle Mechanisms. Journal of Bone and Joint Surgery, 35-A, 115.

Harris, C. Jun., and Riordan, D. C. (1954): Intrinsic Contracture in the Hand and its Surgical Treatment. Journal of Bone and Joint Surgery, 36-A, 10.

Kaplan, E. B. (1953): Functional and Surgical Anatomy of the Hand. Philadelphia: J. B. Lippincott Company. LAGRANGe, J., and Vietre, M. (1954): Le traitement chirurgical des griffes digitales de la lèpre. Semaine des Hôpitaux de Paris, 30, 2,984.

LitTler, J. W. (1949): Tendon Transfers and Arthrodeses in Combined Median Ulnar Nerve Paralysis. Journal of Bone and Joint Surgery, 31-A, 225.

MAYer, L. (1916): The Physiological Method of Tendon Transplantation. Surgery, Gynecology and Obstetrics, 22, 182.

NeY, K. W. (1931): Tendon Transplant for Intrinsic Hand Muscle Paralysis. Surgery, Gynecology and Obstetrics, 33, 342.

Slocum, D. B., and Pratr, D. R. (1926): Disability Evaluation for the Hand. Journal of Bone and Joint Surgery, 28, 491.

Stiles, Sir H. J., and Forrester-Brown, M. F. (1922): Treatment of Injuries of the Peripheral Spinal Nerves, p. 180. London: Henry Frowde and Hodder \& Stoughton. 